\title{
Effect of different salt concentration on the physical properties of frozen thawed egg yolk
}

\author{
KARINA ILONA HIDAS ${ }^{1 *}$ (), CSABA NÉMETH ${ }^{2}$, \\ LIEN PHUONG LE NGUYEN ${ }^{1,3}$, ANNA VISY ${ }^{1}$, ADRIENN TÓTH ${ }^{1}$, \\ LÁSZLÓ FRIEDRICH ${ }^{1}$ and ILDIKÓ CSILLA NYULAS-ZEKE ${ }^{1}$
}

${ }^{1}$ Institute of Food Science and Technology, Hungarian University of Agriculture and Life Sciences, Budapest, Hungary

${ }^{2}$ Capriovus Ltd., Szigetcsép, Hungary

${ }^{3}$ Institute of Biotechnology and Food Technology, Industrial University of Ho Chi Minh City, Ho Chi Minh, Vietnam

\section{CONFERENCE FULL PAPER}

Received: June 1, 2021 • Accepted: July 20, 2021

Published online: August 7, 2021

(C) 2021 The Author(s)

\section{ABSTRACT}

Freezing can enhance the storage time of liquid egg products, but egg yolk undergoes an irreversible textural and structural change when it is cooled to $-6^{\circ} \mathrm{C}$. In this study, the effects of different salt concentrations on the physical properties of frozen-thawed egg yolk were investigated.

The pasteurised liquid egg yolk (LEY) was treated with 4,5 , and $6 \%$ of $\mathrm{NaCl}$ before freezing and it was stored at $-18{ }^{\circ} \mathrm{C}$ for 4 weeks. The colour, $\mathrm{pH}$, and rheological characteristics (firmness, consistency, cohesiveness, and index of viscosity) of yolk samples were evaluated before and after freezing.

Salt treatment resulted in preventing gelation, with decreasing firmness, consistency and viscosity compared to control samples. The $\mathrm{pH}$ of all yolk samples increased during frozen storage. The lightness value decreased in treated samples and increased in the control sample after freezing.

The results indicated that the applied salt concentrations could inhibit protein aggregation of LEY induced by freezing during the storage period. At least $5 \%$ salt concentration could reduce effectively the changes in rheological properties.

\footnotetext{
*Corresponding author. E-mail: hidaskarina@gmail.com
} 


\section{KEYWORDS}

liquid egg yolk, freezing, gelation, back-extrusion rheology, salt concentration

\section{INTRODUCTION}

Eggs are very versatile in the food industry because of their valuable nutrient content and various functional properties. Processed egg products, such as separated, homogenised, and pasteurised liquid egg products are generally used for industrial purposes. Liquid egg yolk (LEY) is a popular ingredient in the food industry because of its gelling, emulsifying, colouring, and coagulating properties, high nutritional value, and unique sensory characteristics. It is often used as a raw material of mayonnaise and confectionery products such as lemon curd, ice cream, créme brulée, and pudding (Cook \& Briggs, 1986; Uysal et al., 2019).

Since egg yolk undergoes a phenomenon called gelation, when it is cooled to $-6^{\circ} \mathrm{C}$ or lower temperatures, the freezing of egg yolk has been a popular topic in numerous researches (Au et al., 2015; Hidas et al., 2021a; Primacella et al., 2018; Wang et al., 2020). The most common explanation of gelation process is that large ice crystals form during the freezing process and it results in the concentration of components, that leads to the accumulation of lowdensity lipoproteins in plasma (Zhao et al., 2021). Au and his co-authors examined the effect of freezing at $-20^{\circ} \mathrm{C}$ and frozen storage for 168 days on the kinetics and gelation process (Au et al., 2015). They found that plasma and granules participate in the irreversible texture change. Wang and his co-authors examined the gelation time of egg yolk at $-18^{\circ} \mathrm{C}$. They found that egg yolk lost its fluidity after $7 \mathrm{~h}$ (Wang et al., 2020).

To prevent the gelation process, antigelation agents can be used. The first study about preventing gelation found that the gelation of yolk can be decreased by the addition of sucrose (Moran, 1925). Other cryoprotectant agents were also effective, sucrose and $\mathrm{NaCl}$ are widely used in 10\% concentration (Lai, 2016). It was indicated that the addition of $5 \%$ salt resulted in a less hard texture than the addition of 10\% (Ma et al., 2021; Primacella et al., 2018).

In this study, different salt concentrations were used within a small range to determine the effect of the different concentrations on the gelation process of the liquid egg yolk. Therefore, 4 , 5 , and $6 \%$ of salt was added to LEY before freezing to determine which concentration is the most effective to reduce the gelation. The $\mathrm{pH}$, colour, and rheological properties of the samples were examined over the storage period.

\section{MATERIALS AND METHODS}

The methods and measurements in this work were performed according to Hidas et al. (2021b).

\section{Materials}

Three kilograms of homogenised, pasteurised LEY $(\mathrm{pH}=6.38 \pm 0.02)$ was obtained from a liquid egg plant (Capriovus Ltd., Szigetcsép, Hungary). The separated and homogenised LEY was pasteurised for $600 \mathrm{~s}$ at $65^{\circ} \mathrm{C}$ with a flow rate of $600 \mathrm{~kg} / \mathrm{h}$. The product was then filled into 'Elopak' carton boxes with a weight of $1.0 \mathrm{~kg}$. The LEY containing no additives should be stored 
between $0{ }^{\circ} \mathrm{C}$ and $4{ }^{\circ} \mathrm{C}$ with a shelf life of 3 days. Before treating, the samples were stored at a temperature of $4^{\circ} \mathrm{C}$.

\section{Sample preparation, freezing and thawing}

Three kilograms of LEY was divided into four equal portions. Salt was added to the LEY to achieve 4,5 and $6 \%(\mathrm{w} / \mathrm{w})$. The portion without the addition of salt served as control sample. The samples were stored at $-18.0 \pm 1.0^{\circ} \mathrm{C}$. The measurements were performed before freezing ( 0 day) and on $14^{\text {th }}$ and $28^{\text {th }}$ days of frozen storage. The frozen yolks were thawed at $4{ }^{\circ} \mathrm{C}$ for $24 \mathrm{~h}$ before measurements.

\section{Determination of $\mathrm{pH}$}

The $\mathrm{pH}$ was measured at $4{ }^{\circ} \mathrm{C}$ using a digital $\mathrm{pH}$ meter (206-pH2, Testo SE \& Co. KGaA, TitiseeNeustadt, Germany) in triplicate.

\section{Colour measurement}

The colour of the samples was measured with a Konica-Minolta CR-410 chromameter (Konica Minolta Sensing Inc., Osaka, Japan) at $4{ }^{\circ} \mathrm{C}$. Measurements were performed five times.

\section{Examination of the rheological properties}

The rheological properties of the LEY samples before freezing and after freezing-thawing were examined by back extrusion rheology. Measurements were performed by a TA.XT plus texture analyser (Stable Micro Systems, Surrey, UK) according to Wang et al. (2020). The back Extrusion Rig of the equipment was used to test the samples. The empty sample container (50 mm diameter) belonging to the Back Extrusion Rig was placed on the locating base plate. A compression disc (35 mm diameter) was positioned centrally over the sample container. The height calibration of the compression disc was performed to the starting distance of $65 \mathrm{~mm}$ from the bottom of the sample container. LEY sample $(80 \mathrm{~mL})$ at the temperature of $4{ }^{\circ} \mathrm{C}$ was filled into the sample container. Measurements were performed at a constant shear velocity of $1 \mathrm{~mm} / \mathrm{s}$. The applied trigger was $5.0 \mathrm{~g}$, the trigger type was automatic. It means, that the machine started to measure the force needed to the constant shear velocity, when $5 \mathrm{~g}$ trigger was detected at the point at which the lower surface of the disc is in full contact with the sample surface. The test distance was $15 \mathrm{~mm}$. When the disc proceeds to penetrate to this depth, after that it returns in the starting position. At the maximum penetration depth, the maximum force is taken as firmness. Consistency is taken as the area under the curve until the maximum penetration depth. When the disc returns to the starting point, the negative region of the graph is produced, because of the sample weight which is lifted on the upper part of the disc. The maximum force measured in the returning phase is an indication of cohesiveness and the area of this region is a measurement of viscosity.

The measurement was repeated 10 times.

\section{Statistical evaluation}

Statistical analysis was performed by IBM Statistics 24 software. The significance level was $5 \%$ $(P<0.05)$ The normality of data was tested by Shapiro-Wilk test $(\mathrm{pH}(\mathrm{k}(36)=0.962 ; P=0.252)$, $\mathrm{L}^{*}(\mathrm{k}(60)=0.962 ; P=0.061), \mathrm{a}^{*}(\mathrm{k}(60)=0.967 ; P=0.110), \mathrm{b}^{*}(\mathrm{k}(60)=0.982 ; P=0.540)$, 
Firmness $(\mathrm{k}(60)=0.989 ; P=0.867)$, Cohesiveness $(\mathrm{k}(60)=0.968 ; P=0.115))$. In the case of the Consistency and Index of viscosity, normality was not proved, so Kruskal-Wallis test was carried out. Levene's test was used for the determination of the equality of variances. Variances were assumed equal in each case: $\mathrm{pH}(\mathrm{F}(11 ; 24)=0.606 ; P=0.805), \mathrm{L}^{*}(\mathrm{~F}(11 ; 48)=1.265 ; P=$ 0.273 , a* $(\mathrm{F}(11 ; 48)=2.028 ; P=0.050), \mathrm{b}^{*}(\mathrm{~F}(11 ; 48)=1.901 ; P=0.063)$, Firmness $(\mathrm{F}(11 ; 48)$ $=0.853 ; P=0.590)$, Consistency $(\mathrm{F}(8 ; 36)=1.945 ; P=0.083)$, Cohesiveness $(\mathrm{F}(11 ; 48)=$ $1.511 ; P=0.159)$, Viscosity index $(\mathrm{F}(8 ; 36)=2.175 ; P=0.053)$. ANOVA was used for the statistical analysis of variances except in the case of the Consistency and Viscosity index. The result of ANOVA test was significant in each case $(P<0.05)$, so Tukey HSD post hoc test was used to decide which groups differ significantly. For Consistency and Viscosity index, Dunn's post hoc test was carried out.

\section{RESULTS AND DISCUSSION}

\section{Changes in $\mathrm{pH}$}

Figure 1 shows the effect of $\mathrm{NaCl}$ on $\mathrm{pH}$ of LEY before freezing and after freezing-thawing.

$\mathrm{NaCl}$ decreased the $\mathrm{pH}$ of sample before freezing. In addition, freezing caused significant changes in $\mathrm{pH}$ of samples. It was observed that $\mathrm{pH}$ of frozen-thawed yolk increased during storage at $-18{ }^{\circ} \mathrm{C}$. The control samples had higher values on all measurement days. The $\mathrm{pH}$ of all samples increased significantly with the increasing of storage time. This finding was similar to other reports (Hidas et al., 2021b; Huang et al., 1997).

\section{Changes in colour parameters}

Changes of colour parameters of LEY are shown in Fig. 2. There was a notable difference between the $\mathrm{L}^{*}$ values of the control sample and the treated group on all measurement days. $\mathrm{NaCl}$ addition remarkably decreased the lightness of the yolk. Freezing caused significant change in $\mathrm{L}^{*}$ values in each sample on each measurement day. An increasing tendency can be seen during the frozen storage. Among the treated group, the $\mathrm{L}^{*}$ of the sample containing $6 \%$ salt was

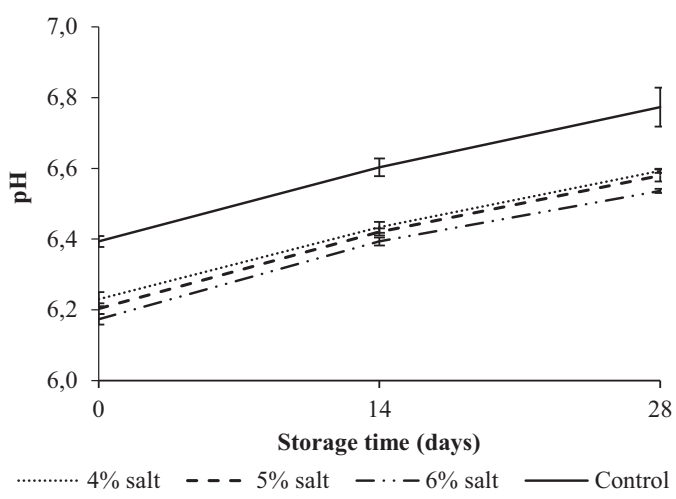

Fig. 1. Effect of different salt concentration on $\mathrm{pH}$ of liquid egg yolk 

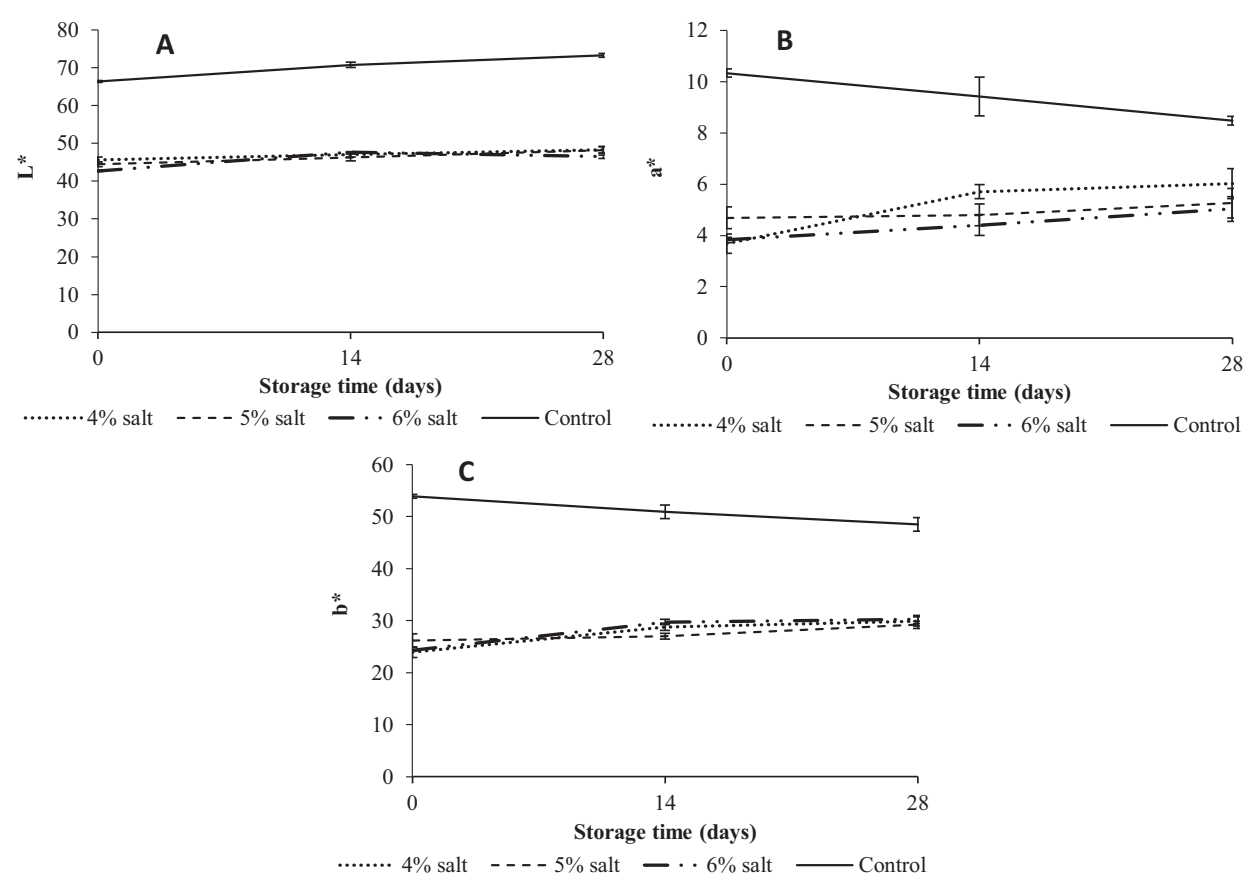

Fig. 2. Effect of different salt concentrations on colour of liquid egg yolk. A - CIE lightness coordinate ( $\left.\mathrm{L}^{\star}\right)$,

$\mathrm{B}-\mathrm{CIE}$ red $(+)$ /green $(-)$ colour attribute $\left(\mathrm{a}^{\star}\right), \mathrm{C}-\mathrm{CIE}$ yellow $(+) /$ blue $(-)$ colour attribute $\left(\mathrm{b}^{*}\right)$

significantly different from the other treated samples before freezing and on 28 , the sample with $5 \%$ salt was significantly different on day 14 . Huang and his co-authors also reported a rising trend of $\mathrm{L}^{*}$ of egg yolk (Huang et al., 1997).

Figure $2 \mathrm{~B}$ shows that there was a significant difference in $\mathrm{a}^{*}$ values between control and treated yolk before freezing and after freezing, $\mathrm{a}^{*}$ values of those samples changed at different rates. The a* values of control samples declined gradually during storage, whereas the frozenthawed salted yolk had an increase in $a^{*}$ values over the storage period. Among the treated group, the $\mathrm{a}^{*}$ of the sample containing $5 \%$ salt was significantly different from the sample containing $4 \%$ salt, the samples with $4 \%$ and $6 \%$ salt differed significantly on day 14 and 28 .

The $b^{*}$ values of LEY were greatly influenced by $\mathrm{NaCl}$ (Fig. 2C). Control samples had higher values in $b^{*}$ compared to treated yolks during storage. There was a notable decrease in $b^{*}$ in the case of the control sample for the whole experiment period, however, the $b^{*}$ values of the treated samples showed an increasing trend. The value of the treated samples also showed an increasing trend, but there was no significant difference between day 14 and 28 in the value of LEY containing $4 \%$ and $6 \%$ salt.

\section{Changes in the rheological behaviour}

The results of the Back-extrusion rheological measurement are shown in Fig. 3. The firmness values of the egg yolk sample did not change significantly when salt was added to it before freezing (Fig. 3A). After freezing and thawing, the firmness of the control sample without salt 

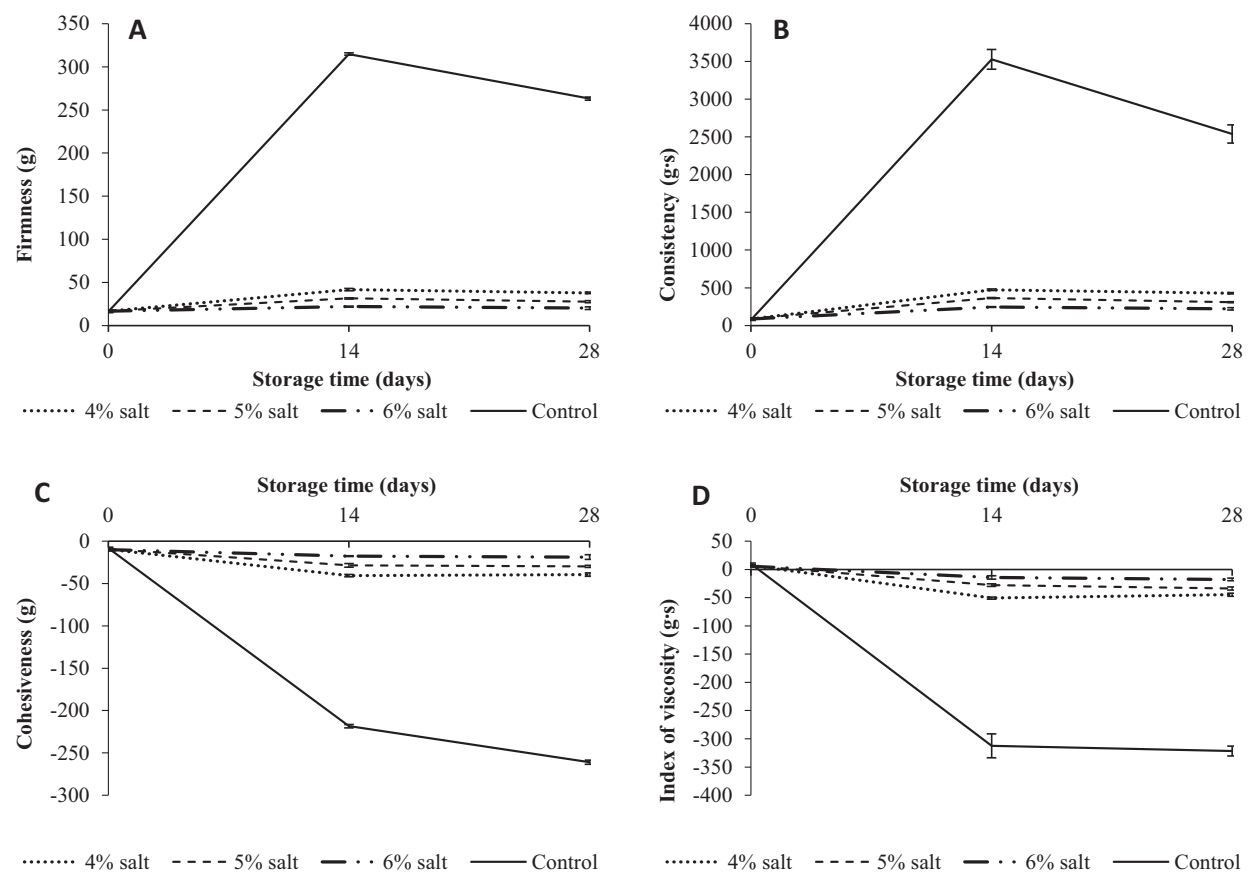

Fig. 3. Effect of salt concentration and frozen storage on the rheological characteristics of frozen-thawed liquid egg yolk. A - Firmness, B - Consistency, C - Cohesiveness, D - Index of viscosity

increased dramatically, although the firmness of the salted yolks was much lower compared to the frozen and thawed control sample. Increasing the salt concentration resulted in significantly lower firmness of frozen-thawed yolk. In the case of samples containing 4 and 5\% salt, a significant decrease can be seen on the $28^{\text {th }}$ day of storage. The firmness of the samples containing $6 \%$ salt had not changed on day 28 .

Figure 3B shows the consistency values of the LEY samples before freezing and after freezing and thawing. Similar trend to the firmness of yolk was observed. No significant difference among samples was found before freezing when salt was added to the LEY. After freezing and thawing, the consistency of the control sample showed a large increase. On the $28^{\text {th }}$ day of frozen storage, a decrease can be seen. Treated samples showed much lower consistency values after freezing and thawing, as well. The values of the control sample were significantly different from the treated samples after freezing and thawing on both measurement days. However, the difference was not significant between the treated samples. The consistency of the control sample and the samples containing 4 and $5 \%$ of salt changed significantly during the experiment, but it did not change in the case of the sample containing $6 \%$ salt.

Cohesiveness values also did not change significantly before freezing when different salt concentrations were used (Fig. 3C). There is a great difference between the control and the treated samples after freezing and thawing. In the case of the control sample, the value of cohesiveness changed considerably during the frozen storage. However, the cohesiveness values of treated samples also changed significantly, but the difference between the fresh and treated 
frozen-thawed samples was much smaller. The more amount of salt the sample contained, the smaller values were obtained. Therefore, the cohesiveness of the sample containing $6 \%$ of salt was the most similar to the fresh LEY sample. The cohesiveness of samples did not change significantly between 14 and 28 days after freezing and thawing.

There was no significant difference in the case of the index of viscosity of the samples before freezing (Fig. 3D). However, the viscosity index of the control sample changed dramatically after freezing and thawing. Significant difference was observed between the fresh and frozen-thawed yolks in the case of the control sample. Among the treated group, there was no significant difference on the $14^{\text {th }}$ and $28^{\text {th }}$ day of the experiment. However, the viscosity index of the samples containing 4 and $5 \%$ of salt was significantly different on day $28^{\text {th }}$ from the other measurement days. The viscosity of the sample of $6 \%$ salt did not change during the experiment. In addition, the viscosity of the sample containing $6 \%$ salt was the nearest to the viscosity of fresh LEY sample.

Physical properties, such as firmness, consistency, cohesiveness and viscosity index of LEY are important factors affecting the processing line. Previous studies (Primacella et al., 2018) also reported that the rheological properties of LEY were more similar to the fresh egg yolk when salt is added. Low-density lipoproteins suffer from aggregation process during freezing because of water removal due to ice formation. Freezing of liquid egg yolk containing salt at temperatures higher than the eutectic point can inhibit the gelation process. This leads to the conclusion that salt can form complexes with water and LDL (Primacella et al., 2018; Chang et al., 1977).

\section{CONCLUSIONS}

$\mathrm{NaCl}$ treatment caused several changes in physical properties of LEY before and after freezing. However, $\mathrm{NaCl}$ could prevent the gelation of pasteurised liquid egg yolk after freezing. The results presented in this study showed that salt treatment greatly influenced firmness, consistency, cohesiveness and viscosity index of frozen-thawed egg yolk. Treatment was found successful in inhibiting protein aggregation of egg yolk, as it was reflected by monotonously different parameter values following salt concentration. Addition of 5 or $6 \%$ of $\mathrm{NaCl}$ could decrease protein aggregation induced by freezing.

\section{ACKNOWLEDGEMENTS}

We owe the colleagues of the Institute of Food Science and Technology and Capriovus Ltd. all thanks. Our research is supported by the KFI_16-1-2017-0551, VEKOP-2.1.1-15-2016-00149 and EFOP-3.6.3-VEKOP-16-2017-00005 projects, for which we are very thankful. The authors acknowledge the Doctoral School of Food Science of the Hungarian University of Agriculture and Life Sciences for the support in this study.

\section{REFERENCES}

Au, C., Acevedo, N. C., Horner, H. T., and Wang, T. (2015). Determination of the gelation mechanism of freeze-thawed hen egg yolk. Journal of Agricultural and Food Chemistry, 63(46): 10170-10180. 
Chang, C. H., Powrie, W. D., and Fennema, O. (1977). Studies on the gelation of egg yolk and plasma upon freezing and thawing. Journal of Food Sciences, 42: 1658-1665.

Cook, F. and Briggs, G. M. (1986). The nutritive value of egg. In: Stadelman, W. J. and Cotterill, O. J. (Eds.), Egg science and technology. Food Products Press, pp. 141-164.

Hidas, K. I., Németh, Cs., Nguyen, L. L. P., Visy, A., Tóth, A., Barkó, A., Friedrich, L., Nagy, A., and Nyulas-Zeke, I. Cs. (2021a). Effect of cryogenic freezing on the rheological and calorimetric properties of pasteurized liquid egg yolk. Czech Journal of Food Sciences, 39: 181-188.

Hidas, K. I., Nyulas-Zeke, I. C., Visy, A., Baranyai, L., Nguyen, L. P. L., Tóth, A., Friedrich, L., Nagy, A., and Németh, C. (2021b). Effect of combination of salt and $\mathrm{pH}$ on functional properties of frozen-thawed egg yolk. Agriculture, 11(3): 257.

Huang, S., Herald, T., and Mueller, D. (1997). Effect of electron beam irradiation on physical, physiochemical, and functional properties of liquid egg yolk during frozen storage. Poultry Science, 76(11): $1607-1615$.

Lai, L.-S. (2016). Quality and safety of frozen eggs and egg products. In: Sun, D.-W. (Ed.), Handbook of frozen food processing and packaging. CRC Press, pp. 529-548.

Ma, Z., Ma, Y., Wang, R., and Chi, Y. (2021). Influence of antigelation agents on frozen egg yolk gelation. Journal of Food Engineering, 302: 110585.

Moran, T. (1925). The effect of low temperature on hens' eggs. Proceedings of the Royal Society of London. Series B, Containing Papers of a Biological Character, 98(691): 436-456.

Primacella, M., Fei, T., Acevedo, N., and Wang, T. (2018). Effect of food additives on egg yolk gelation induced by freezing. Food Chemistry, 263: 142-150.

Uysal, R. S., Sumnu, G., and Boyaci, I. H. (2019). Effects of heat-treated liquid whole egg on cake batter rheology and the quality of baked cake. Journal of Food Process Engineering, 42(2): e12977.

Wang, R., Ma, Y., Ma, Z., Du, Q., Zhao, Y., and Chi, Y. (2020). Changes in gelation, aggregation and intermolecular forces in frozen-thawed egg yolks during freezing. Food Hydrocolloids, 108: 105947.

Zhao, Y., Feng, F., Yang, Y., Xiong, C., Xu, M., and Tu, Y. (2021). Gelation behavior of egg yolk under physical and chemical induction: a review. Food Chemistry, 355: 129569.

Open Access. This is an open-access article distributed under the terms of the Creative Commons Attribution 4.0 International License (https://creativecommons.org/licenses/by/4.0/), which permits unrestricted use, distribution, and reproduction in any medium, provided the original author and source are credited, a link to the CC License is provided, and changes - if any - are indicated. (SID_1) 